JGG 2021;69:292-295

doi: $10.36150 / 2499-6564-N 464$

Clinical Geriatrics - Reviews

\title{
Surgery in older patients with diabetes
}

\author{
Raffaele Antonelli Incalzi \\ Department of Internal Medicine, Campus Bio-Medico University, Rome, Italy; Italian Society of \\ Gerontology and Geriatrics, Florence, Italy
}

\section{RECOMMENDATIONS}

Patients could be divided into three groups:

1 patients with known diabetes mellitus prior to hospitalization;

2 patients with a first diagnosis of diabetes mellitus made during their stay, which continues after discharge;

3 patients with hyperglycemia related to hospitalization or surgery: they are non-diabetic individuals with hyperglycemia that appears for the first time during hospitalization but does not persist after discharge.

For these patients the suggested actions are:

- To assess the risk-benefit ratio of the surgical procedure in relation to the patient's age, comorbidities, and life expectancy through a Comprehensive Geriatric Assessment. To this aim, where available, a multidisciplinary team of geriatricians, endocrinologists, surgeons, and anesthesiologists is useful for improving risk stratification and prevention (see themes 6 and 7) (groups 1-3).

- To implement pre-hospitalization protocols for patients with known diabetes who need to undergo elective surgery, to maintain a stable metabolic condition (group 1).

Received: July 30, 2021

Accepted: September 16, 2021

\section{Correspondence}

Raffaele Antonelli Incalzi

Department of Internal Medicine, Campus BioMedico University, via Alvaro del Portillo 21, 00128 Rome, Italy

E-mail: r.antonelli@unicampus.it

How to cite this article: Antonelli Incalzi R. Surgery in older patients with diabetes. Journal of Gerontology and Geriatrics 2021;69:292-295. https://doi. org/10.36150/2499-6564-N464

(C) Copyright by Società Italiana

di Gerontologia e Geriatria (SIGG)

\section{(c) (1) () $(9)$}

\section{OPEN ACCESS}

This is an open access article distributed in accordance with the CC-BY-NC-ND (Creative Commons Attribution-NonCommercial-NoDerivatives 4.0 International) license. The article can be used by giving appropriate credit and mentioning the license, but only for non-commercial purposes and only in the original version. For further information: https://creativecommons.org/licenses/by-nc-nd/4.0/deed.en

- To carry out diabetes screening for patients without a diabetes mellitus diagnosis prior to admission for elective surgery (groups 2 and 3).

- To check and optimize pre- and peri-operative glycemic lowering drugs in persons with a known diagnosis of diabetes mellitus (group 1).

- Define a peri-operative glycemic target range of $100-180 \mathrm{mg} / \mathrm{dl}$. In particular, the CIS and American Diabetes Association suggest targets of $<140 \mathrm{mg} / \mathrm{dl}$ for fasting glucose and up to $180 \mathrm{mg} / \mathrm{dl}$ during the day ${ }^{1}$ (groups 1-3).

- Monitor glucose during the patient's hospital stay: capillary glycaemia should be checked every 4-6 hours for non-critical patients who are unable to feed themselves, while those who regularly eat should be checked preprandially, postprandially, and before they lie down. If the patient is undergoing continuous intravenous infusion, they must be checked every 1-2 hours ${ }^{2}$. The frequency of checks can be reduced (every 4 hours) once glucose levels are stabilized and the infusion rate can be calculated using as algorithm such as the one from Yale University (Goldberg PA, 2005) ${ }^{2}$. Continuous glucose monitoring is not yet recommended during hospitalization ${ }^{3}$ (groups 1-3).

- Basal-bolus therapy is the recommended drug regimen for hospitalized diabetic patients, even in hyperglycemic patients without a diagnosis of diabetes (groups 1-3).

\section{STRENGTH OF THE RECOMMENDATIONS}

The quality of the evidence is moderate. Recommendations are supported 
by published evidence and best practice (supported by expert opinion).

\section{SUPPORTING EVIDENCE}

See appendix.

\section{AREAS OF UNCERTAINTY AND FUTURE PERSPECTIVES}

In multimorbid, disabled and clinically unstable patients less stringent glycemic targets might be and occasionally are pursued. However, a consensus of opinion about this topic would be desirable.

The safe transition from inpatient to outpatient setting requires a personalized plan. It would be useful to identify patients for whom a comprehensive geriatric assessment at discharge should be preferred to usual care.

\section{APPENDIX}

\section{WHAT RECOMMENDATIONS FOR EMERGENCY OR ELECTIVE SURGERY ARE SUGGESTED FOR PATIENTS WITH DIABETES OVER THE AGE OF 75 ?}

Out of the approximately 422 million people with diabetes worldwide (Global Report on Diabetes, WHO 2016), more than 65\% are over 65 years old and more than 30\% are 75 years or older. Given the direct relationship between age and surgical diseases, the need for surgical procedures among diabetics is likely to increase considerably, especially over $75^{4}$. Today, $10 \%$ of patients undergoing surgery have a diagnosis of diabetes ${ }^{5}$. Observational studies report that the prevalence of hyperglycemia in patients undergoing surgery, regardless of whether they had a previous diabetes diagnosis, is $32-38 \%{ }^{6}$, and $80 \%$ in cardiac surgery patients ${ }^{7}$. On average, the mortality rate for the surgical population is $50 \%$ higher in persons with diabetes compared to those without ${ }^{8-10}$.

Studies in the literature report an association between diabetes mellitus and increased risk of post-operative infection ${ }^{11,12}$, wound complications ${ }^{13}$, cardiovascular events, and venous thromboembolism ${ }^{14,15}$. Diabetes mellitus is also associated with an increased incidence of complications and reoperations ${ }^{16}$, post-operative kidney failure ${ }^{17}$, and prolonged hospital stay ${ }^{8,18}$, leading to increased hospitalization costs.

Studies have compared the outcomes of patients with and without diabetes, based on their pre-and perioperative glycemic values, according to surgery type.
Some analyses ${ }^{19}$ have shown that type II patients with moderate glycemic control (150-200 mg/dl) undergoing non-cardiac surgery have comparable mortality and post-operative complications to individuals with wellcontrolled glycemia $(<150 \mathrm{mg} / \mathrm{dl})$ and lower than those with poor glycemic control (> $200 \mathrm{mg} / \mathrm{dl}$ ). Stricter blood control, therefore, does not appear to be necessary in this type of patients. In contrast, randomized controlled trials, in the field of cardiac surgery, have shown that glycemic values of $100-140 \mathrm{mg} / \mathrm{dl}$ are associated with fewer pre- and post-operative complications ${ }^{20}$. In both surgical and non-surgical cases, $12-38 \%$ of patients receiving insulin therapy are hypoglycemic ${ }^{21}$. The development of hypoglycemia, especially in persons over 75 , has been associated with longer illness duration and increased in-hospital mortality ${ }^{22-24}$.

Studies on pre- and perioperative glycaemia values ${ }^{25-27}$ found an increase in the risk of adverse events related to hyperglycemia in non-diabetic patients, but no association among those with diabetes.

$\mathrm{HbA1c}$, which reflects glycemic values over the preceding 90 days, could be used to stratify surgical risk. Most guidelines recommend a value of between 8-9\% $(68-75 \mathrm{mmol} / \mathrm{mol})$ as a safe target ${ }^{28}$. Among the many studies on pre-operative $\mathrm{HbA} 1 \mathrm{c}$ as the only predictive value for post-operative complications, the largest retrospective study was conducted by Adam and colleagues ${ }^{29}$ on 40,491 prosthetic knee patients, including 23,924 non-diabetics, 5042 diabetics with HbA1c $<7 \%$, and 2525 diabetics with $\mathrm{HbA} 1 \mathrm{c}>7 \%$. Five complications were assessed: 1) revision arthroplasty within one year; 2) infection of the prosthesis within one year; 3) deep venous thrombosis/pulmonary embolism within 90 days; 4) myocardial infarction within one year; 5) allcause hospitalization within one year. No complications were found to be significantly more frequent in any of the three groups. In particular, total complications were $37 \%(1877 / 5042)$ for those with good glycemic control $(\mathrm{HbA} 1 \mathrm{c}<7 \%)$ and 34\% (857/2525) for those with poor glycemic control. It is known that pre-operative HbA1c values are not in themselves reliable predictors but may be part of a comprehensive patient assessment including age, Body Mass Index, diabetes complications, and comorbidities ${ }^{30,31}$.

However, the average age of the population analyzed in the literature is between 60 and 65 years. Older people are often excluded from such studies even though 23\% of persons aged 75 and over undergo surgery ${ }^{32}$. In fact, only $1.4 \%$ of trials recruit such individuals ${ }^{33}$. Thus, there is limited current knowledge on a population in which diabetes treatment suffers from multimorbidity and polypharmacy, with related risks of adverse events and/or interactions. In addition, patients aged 75+ who undergo surgery have greater post-operative mortality 
and an increased risk of complications, both for elective and emergency surgery ${ }^{34}$. Finally, frailty, which is highly prevalent in persons with type II diabetes ${ }^{35,36}$, is associated with negative peri-operative outcomes. Identifying frailty could help risk stratification for preoperative preparation and post-operative management, but evidence is lacking for this specific population.

Insulin is the basis for hyperglycemia treatment. Basalbolus is the preferred treatment regimen for hospitalized patients, i.e., the use of rapid insulin injections before meals in addition to basal insulin. The RABBIT study showed that, compared to Sliding Scale Insulin (SSI), the basal-bolus method is associated with a reduced incidence of surgical site infection, pneumonia, and respiratory or kidney failure. Despite a better glycemic control, moderate hypoglycemia ( $<70 \mathrm{mg} / \mathrm{dl})$ occurred more frequently with the basal bolus regimen. Some non-insulin glucose lowering agents, such as DPP-IV inhibitors, in monotherapy or in combination with basal insulin, could be viable alternatives, especially in older people ${ }^{2}$. Other glucose lowering agents should be avoided in the hospital environment. In particular, the AIFA-AMD-SID Joint Guidelines suggest suspending metformin treatment two days prior to and one day after surgery, replacing it with basal-bolus insulin therapy if necessary.

There are no randomized studies comparing the use of continuous subcutaneous insulin infusion (CSII) with the basal-bolus regimen. The current advice is to suspend CSIl at hospital admission and switch to basal-bolus treatment. Intravenous insulin therapy is mainly indicated for the treatment of perioperative hyperglycemia in cardiac surgery, organ transplantation, and cardiogenic shock, as well as during high-dose steroid therapy and parenteral nutrition ${ }^{2}$. Two or three hours before the end of the intravenous insulin therapy, the basal regimen should be administered, using the amount of insulin injected in the last 24 hours as a base for estimating the dose ${ }^{37}$.

\section{Ethical consideration}

None.

\section{Acknowledgement}

None.

\section{Funding}

None.

\section{Conflict of interest}

The Author declares no conflict of interest.

\section{References}

1 Goldberg PA, Inzucchi SE. Clarification - improving glycemic control in the cardiothoracic intensive care unit: clinical experience in two hospital settings. J Cardiothorac Vasc Anesth 2005;19:416-417. https://doi.org/10.1053/j. jvca.2005.02.001

2 Medical Diabetologist Association, Italian Society of Diabetology. Italian Standards for diabetes mellitus care, 2018. Published online 04/27/2018 (https://aemmedi.it/wp-content/uploads/2009/06/AMD-Standard-unico1.pdf).

3 Gomez AM, Umpierrez GE. Continuous glucose monitoring in insulin-treated patients in non-ICU settings. J Diabetes Sci Technol 2014;8:930-936. https://doi. org/10.1177/1932296814546025

4 Buchleitner AM, Martínez-Alonso M, Hernández M, et al. Perioperative glycaemic control for diabetic patients undergoing surgery. Cochrane Database Syst Rev 2012:CD007315. https://doi.org/10.1002/14651858. cd007315.pub2

5 NHS Diabetes. Management of adults with diabetes undergoing surgery and elective procedures: improving standards, April 2011 (http://www.diabetologists-abcd. org.uk/jbds/JBDS_IP_Surgery_Adults_Full.pdf).

6 Cook CB, Kongable GL, Potter DJ, et al. Inpatient glucose control: a glycemic survey of 126 U.S. hospitals. J Hosp Med 2009;4:E7-E14. https://doi.org/10.1002/jhm.533

7 Schmeltz LR, DeSantis AJ, Thiyagarajan V, et al. Reduction of surgical mortality and morbidity in diabetic patients undergoing cardiac surgery with a combined intravenous and subcutaneous insulin glucose management strategy. Diabetes Care 2007;30:823-828. https://doi.org/10.2337/ dc06-2184

8 Smiley DD, Umpierrez GE. Perioperative glucose control in the diabetic or nondiabetic patient. South Med J 2006;99:580-589; quiz 590-1. https://doi.org/10.1097/01. smj.0000209366.91803.99

9 Frisch A, Chandra P, Smiley D, et al. Prevalence and clinical outcome of hyperglycemia in the perioperative period in noncardiac surgery. Diabetes Care 2010;33:1783-1788. https://doi.org/10.2337/dc10-0304

10 Visser A, Geboers B, Gouma DJ, et al. Predictors of surgical complications: a systematic review. Surgery 2015;158:5865. https://doi.org/10.1016/j.surg.2015.01.012

11 Fisichella L, Fenga D, Rosa MA. Surgical site infection in orthopaedic surgery: correlation between age, diabetes, smoke and surgical risk. Folia Med (Plovdiv) 2014;56:259263. https://doi.org/10.1515/folmed-2015-0005

12 Lee QJ, Mak WP, Wong YC. Risk factors for periprosthetic joint infection in total knee arthroplasty. J Orthop Surg (Hong Kong) 2015;23:282-286. https://doi. org/10.1177/230949901502300303

13 Moon HK, Han DG, Yang $\mathrm{H}$, et al. Factors affecting outcome after total knee arthroplasty in patients with diabetes mellitus. Yonsei Med J 2008;49:129-137. https://doi. org/10.3349/ymj.2008.49.1.129

14 Wang S, Zhao Y. Diabetes mellitus and the incidence of deep vein thrombosis after total knee arthroplasty: a retrospective study. J Arthroplasty. 2013;28:595-597. https:// doi.org/10.1016/j.arth.2012.07.023

15 Zhao Z, Wang S, Ma W, et al. Diabetes mellitus increases 
the incidence of deep vein thrombosis after total knee arthroplasty. Arch Orthop Trauma Surg 2014;134:79-83. https://doi.org/10.1007/s00402-013-1894-3

16 Brant JA, Bur AM, Chai R, et al. Reoperation following adult tonsillectomy: review of the american college of surgeons national surgical quality improvement program. Otolaryngol Head Neck Surg 2016;154:779-784. https:// doi.org/10.1177/0194599816630239

17 Gumus F, Polat A, Sinikpglu SN, et al. Use of a lower cutoff value for $\mathrm{HbA} 1 \mathrm{c}$ to predict postoperative renal complication risk in patients undergoing coronary artery bypass grafting. J Cardiothorac Vasc Anesth 2013;27:1167-1173. https://doi.org/10.1053/j.jvca.2013.02.030

18 Sivrikoz E, Karamanos E, Beale E, et al. The effect of diabetes on outcomes following emergency appendectomy in patients without comorbidities: a propensity scorematched analysis of National Surgical Quality Improvement Program database. Am J Surg 2015;209:206-211. https:// doi.org/10.1016/j.amjsurg.2014.03.015

19 Sathya B, Davis R, Taveira T, et al. Intensity of peri-operative glycemic control and postoperative outcomes in patients with diabetes a meta-analysis. Diabetes Res Clin Pract2013;102:815. https://doi.org/10.1016/j.diabres.2013.05.003

20 American Diabetes Association. Standards of medical care in diabetes, 2013. Diabetes Care 2013;36(Suppl 1):S11S66. https://doi.org/10.2337/dc13-s011

21 Umpierrez GE, Smiley D, Jacobs S, et al. Randomized study of basal-bolus insulin therapy in the inpatient management of patients with type 2 diabetes undergoing general surgery (RABBIT 2 surgery). Diabetes Care 2011;34:256-261. https://doi.org/10.2337/dc10-1407

22 Kagansky N, Levy S, Rimon E, et al. Hypoglycemia as a predictor of mortality in hospitalized elderly patients. Arch Intern Med 2003;163:1825-1829. https://doi.org/10.1001/ archinte.163.15.1825

23 Shilo S, Berezovsky S, Friedlander Y, et al. Hypoglycemia in hospitalized nondiabetic older patients. J Am Geriatr Soc 1998;46:978-982. https://doi. org/10.1111/j.1532-5415.1998.tb02752.x

24 Farrokhi F, Klindukhova O, Chandra $P$, et al. Risk factors for inpatient hypoglycemia during subcutaneous insulin therapy in non-critically ill patients with type 2 diabetes. J Diabetes Sci Technol 2012;6:1022-1029. https://doi. org/10.1177/193229681200600505

25 Kotagal M, Symons RG, Hirsch IB, et al. Perioperative hyperglycemia and risk of adverse events among patients with and without diabetes. Ann Surg 2015;261:97-103. https://doi.org/10.1097/sla.0000000000000688

26 Lauruschkat AH, Arnrich B, Albert AA, et al. Prevalence and risks of undiagnosed diabetes in patients undergoing coronary artery bypass grafting. Circulation 2005;112:23972402. https://doi.org/10.1161/circulationaha.105.534545

27 Sathya B, Davis R, Taveira T, et al. Intensity of peri-operative glycemic control and postoperative outcomes in patients with diabetes a meta-analysis. Diabetes Res Clin Pract 2013;102:815. https://doi.org/10.1016/j.diabres.2013.05.003

28 Dhatariya K, Levy N, Kilvert A, et al. NHS Diabetes guideline for the perioperative management of the adult patient with diabetes. Diabetes Med 2012;29:420-433. https:// doi.org/10.1111/j.1464-5491.2012.03582.x

29 Cancienne JM, Brockmeier SF, Werner BC. Association of perioperative glycemic control with deep postoperative infection after shoulder arthroplasty in patients with diabetes. J Am Acad Orthop Surg 2018;26:e238-e245. https:// doi.org/10.5435/jaaos-d-16-00784

30 Lopez LF, Reaven PD, Harman SM. Review: the relationship of hemoglobin A1c to postoperative surgical risk with an emphasis on joint replacement surgery. J Diabetes Complications 2017;31:1710-1718. https://doi.org/10.1016/j. jdiacomp.2017.08.016

31 Cancienne JM, Werner BC, Browne JA. Is there an association between hemoglobin A1C and Deep postoperative infection after TKA? Clin Orthop Relat Res 2017;475:1642 1649. https://doi.org/10.1007/s11999-017-5246-4

32 Office for National Statistics. Estimates of the very old (including centenarians): England and Wales, and United Kingdom, 2002 to 2014 (https://www.ons.gov.uk/peoplepopulationandcommunity/birthsdeathsandmarriages/ageing/bulletins/ estimatesoftheveryoldincludingcentenarians/2015-09-30).

33 Cederholm T, Cruz-Jentoft AJ, Maggi S. Sarcopenia and fragility fractures. Eur J Phys Rehabil Med 2013;49:111-117.

34 Lin H-S, Watts JN, Peel NM, et al. Frailty and post-operative outcomes in older surgical patients: a systematic review. BMC Geriatr 2016;16:157. https://doi.org/10.1186/ s12877-016-0329-8

35 Thein FS, Li Y, Nyunt MSZ, et al. Physical frailty and cognitive impairment is associated with diabetes and adversely impact functional status and mortality. Postgrad Med 2018;130:561 567. https://doi.org/10.1080/00325481.2018.1491779

36 Ogurtsova K, da Rocha Fernandes JD, Huang Y, et al. IDF diabetes atlas: global estimates for the prevalence of diabetes for 2015 and 2040. Diabetes Res Clin Pract 2017;128:40-50. https://doi.org/10.1016/j. diabres.2017.03.024

37 Avanzini F, Marelli G, Donzelli W, et al. Transition from intravenous to subcutaneous insulin: effectiveness and safety of a standardized protocol and predictors of outcome in patients with acute coronary syndrome. Diabetes Care 2011;34:1445-1450. https://doi.org/10.2337/dc10-2023

\author{
This statement is: \\ 囚 Recommendation (supported by published evidence) \\ $\bowtie$ Best practice (supported by expert opinion)
}

Quality of the evidence (in the case of recommendation):
$\square$ Low
$\bigotimes$ Moderate
$\square$ High

Quality of the evidence (in the case of recommendation):

Moderate 